\title{
Treatment mechanism of matrine in combination with irinotecan for colon cancer
}

\author{
LING DUAN $^{1}$, LEIJIAO DENG $^{2}$, DABIN WANG $^{3}$, SHOUCHENG MA $^{1}$, CHUNMEI LI $^{1}$ and DA ZHAO ${ }^{1}$ \\ Departments of ${ }^{1}$ Oncology and ${ }^{2}$ Pharmacy, The First Hospital of Lanzhou University; ${ }^{3}$ Department \\ of Anesthesiology, The People's Hospital of Gansu Province, Lanzhou, Gansu 730000, P.R. China
}

Received January 30, 2017; Accepted May 25, 2017

DOI: $10.3892 / \mathrm{ol} .2017 .6407$

\begin{abstract}
The inhibitory effect of matrine (MA) was studied in combination with irinotecan (CPT-11) on proliferation of human colon carcinoma cell line HT29. We also explored the mechanism of cell apoptosis induction in HT29. HT29 cells were treated with different concentrations of MA and CPT-11 alone and in combination. The growth inhibition in HT29 cells was evaluated using MTT assay. Apoptosis was detected using AV-PI double staining flow cytometry. Transmission electron microscopy was used to detect structural changes in cells. Topoisomerase (TOPO) I, Bax and Caspase-3 expression levels were evaluated using western blot analysis. MA and CPT-11 alone and in combination, inhibited the proliferation of HT29 cells, whereas the combination treatment exhibited higher inhibitory effect $(\mathrm{P}<0.01)$. This suggests the existence of synergistic cytotoxicity. Compared with each treatment alone, the combination treatment caused more significant damage to cell structure, and caused a significantly higher apoptosis rate $(\mathrm{P}<0.01)$. Additionally, the combination treatment increased TOPO I, Bax and Caspase-3 expression levels $(\mathrm{P}<0.01)$. In conclusion, MA in combination with CPT-11 synergistically inhibited HT29 cell proliferation and induced apoptosis in these cells. The mechanism may be related to upregulation of the TOPO I, Bax and Caspase-3 protein expression.
\end{abstract}

\section{Introduction}

Colon cancer is one of the most common intestinal malignancies, ranking third in gastrointestinal cancers. In recent years, colon cancer incidence has been on the increase annually due to changes in people's lifestyle and diet (1). Patients with colon cancer do not show obvious early symptoms. Most patients are diagnosed during intermediate and late stages, and approximately $35 \%$ of patients are diagnosed during late stage.

Correspondence to: Dr Da Zhao, Department of Oncology, The First Hospital of Lanzhou University, 1 Donggang West Road, Chengguan, Lanzhou, Gansu 730000, P.R. China

E-mail: zbo662@163.com

Key words: matrine, irinotecan, colon cancer, HT29 cells, apoptosis
Patients experienced high incidence of metastasis and recurrence within 5 years after surgery (1). At present, the treatment of colon cancer is largely surgery-based, followed by adjuvant chemotherapy. However, chemotherapy often leads to drug resistance in colon cancer patients who experience adverse effects as well, thereby affecting the efficacy of chemotherapy and patient life quality (2).

Irinotecan (CPT-11), a DNA topoisomerase (TOPO) inhibitor, becomes effective after it is metabolized to 7-ethyl-10-hydroxycamptothecin (SN-38) in vivo. The metabolite SN-38 binds specifically to DNA TOPO, breaking the DNA double-strand structure and eventually leading to apoptosis $(3,4)$. At present, CPT-11 is used as the first-line chemotherapy drug for patients with colorectal cancer, but patients usually experience serious adverse effects including delayed diarrhea. Thus, clinical applications of CPT-11 are limited (5). Matrine (MA) is a natural compound extracted from root of Sophora flavescens with a wide range of pharmacological activities including antihepatic fibrosis, anti-viral, anti-arrhythmic, anti-inflammation and anti-tumor (6). It was discovered that MA can inhibit cell growth in different types of cancer including gastric, cervical, lung, liver, breast, and colon cancer $(7,8)$.

It was reported that MA could function synergistically with chemotherapeutic drugs, not only enhancing chemotherapeutic effects, but also reversing chemotherapy drug resistance (9). Previous findings showed that MA can enhance the treatment of CPT-11 in patients with colorectal cancer, and reduce the adverse effects of CPT-11 (10). However, the molecular mechanism of the combination treatment of MA and CPT-11 in colon cancer has not been studied adequately.

In order to evaluate the synergistic inhibitory effects of the combination treatment and the underlying molecular mechanisms, in the present study, we treated colon cancer cells HT29 with MA in combination with CPT-11. Our results provided some experimental basis for colon cancer treatment using the combination therapy of MA and CPT-11.

\section{Materials and methods}

Materials. The following cells, reagents and supplies were purchased from commercial sources: MA and CPT-11 from Aladdin Reagents Co., Ltd. (Shanghai, China); human colon cancer HT29 cells from Cell Bank of the Chinese Academy of Sciences (Shanghai, China); RPMI-1640 medium and fetal 
bovine serum (FBS) from HyClone Laboratories, Inc. (Logan, UT, USA); TOPO I, Bax, Caspase-3, GAPDH primary antibody, and HRP-labeled secondary antibody from Proteintech Group, Inc. (Wuhan, China); cell lysis solution, BCA protein concentration assay kit, and Annexin V-FITC apoptosis detection kit from Beyotime Institute of Biotechnology (Nantong, China). This study was approved by the Ethics Committee of The First Hospital of Lanzhou University.

Cell culture. HT29 cells were incubated in RPMI-1640 medium containing $100 \mathrm{U} / \mathrm{ml}$ of penicillin, $100 \mu \mathrm{g} / \mathrm{ml}$ of streptomycin and $10 \% \mathrm{FBS}$ at $37^{\circ} \mathrm{C}$ with $5 \% \mathrm{CO}_{2}$. When the cell growth reached the log growth phase, the cells were treated with trypsin to obtain a single cell suspension, and then were seeded into different culture plates or culture dishes for group experiments according to the experimental requirements.

MTT assay determination of survival rate of HT29 cells. The study was divided into the experimental group and the normal control group. MA and CPT-11 were dissolved in DMSO. HT29 cells in the logarithmic growth phase were collected and seeded into a 96 -well plate at $200 \mu \mathrm{l}$ of $1 \times 10^{4}$ cells $/ \mathrm{ml}$ cell suspension. After $24 \mathrm{~h}$ incubation, the experimental group was further divided into 12 subgroups for different treatments: 4 subgroups for MA treatment alone with final MA concentrations of 0.25 , $0.5,1.0$ and $2.0 \mathrm{mg} / \mathrm{ml}$; 4 subgroups for CPT-11 treatment alone with final CPT-11 concentrations of 1.25,2.5,5.0 and $10.0 \mu \mathrm{g} / \mathrm{ml}$; and 4 subgroups for combination treatment with final concentrations of $0.25 \mathrm{mg} / \mathrm{ml} \mathrm{MA}+1.25 \mu \mathrm{g} / \mathrm{ml} \mathrm{CPT}-11,0.5 \mathrm{mg} / \mathrm{ml}$ $\mathrm{MA}+2.5 \mu \mathrm{g} / \mathrm{ml} \mathrm{CPT}-11,1.0 \mathrm{mg} / \mathrm{ml} \mathrm{MA}+5 \mu \mathrm{g} / \mathrm{ml} \mathrm{CPT}-11$, and $5.0 \mathrm{mg} / \mathrm{ml} \mathrm{MA}+10.0 \mu \mathrm{g} / \mathrm{ml} \mathrm{CPT}-11$. Five wells was set for each concentration. Equal volumes of culture medium were added to wells for the normal control group. After $24 \mathrm{~h}$, the culture medium was discarded, and wells were washed 3 times with PBS, followed by addition of $100 \mu \mathrm{l}$ of MTT $(5 \mathrm{mg} / \mathrm{ml})$ per well and incubation for $4 \mathrm{~h}$. DMSO $(100 \mu \mathrm{l})$ was added to each well, followed by agitation for $10 \mathrm{~min}$ in the dark and measurement of absorbance value (OD value) at $570 \mathrm{~nm}$ by ELISA. The cell inhibition rate was calculated using the formula: inhibition rate $(\%)=100 \times($ OD value of normal control group - OD value of experimental group)/OD value of normal control group.

Analysis of apoptosis. Based on the MTT assay results, an appropriate drug concentration was chosen that provided a 20-30\% inhibition rate $\left(\mathrm{IC}_{20}-\mathrm{IC}_{30}\right)$ for the experiment. Cells were divided into 4 groups: the normal control group (control), the MA group (concentration $0.5 \mathrm{mg} / \mathrm{ml}$ ), the CPT-11 group (concentration $1.25 \mu \mathrm{g} / \mathrm{ml}$ ), and the combination group (MA $0.5 \mathrm{mg} / \mathrm{ml}+$ CPT-11 $1.25 \mu \mathrm{g} / \mathrm{ml})$. HT29 cells in the logarithmic phase were seeded into a 6-well plate. After attachment, the cells were treated with different drugs at the selected concentration described above. After $24 \mathrm{~h}$ of incubation, the cells were washed 3 times with PBS, followed by trypsin digestion and centrifugation. We closely followed the instructions provided in the apoptosis detection kit by the manufacturer. The collected cells were re-suspended in $0.3 \mathrm{ml}$ binding buffer, followed by the addition of $5 \mu \mathrm{l}$ Annexin $\mathrm{V}$ and $5 \mu \mathrm{l}$ PI. After $15 \mathrm{~min}$ of incubation at room temperature in the dark, samples were diluted with $0.2 \mathrm{ml}$ of binding buffer and analyzed by flow cytometry (Becton-Dickinson, New York, NY, USA).
Transmission electron microscope observation of cell ultrastructure change. Cells were treated and collected according to the method explained above. Cell pellet was immersed in $2.5 \%$ glutaraldehyde and left at $4^{\circ} \mathrm{C}$ for $48 \mathrm{~h}$. After cell fixation, the sample was treated with osmium tetroxide for $30 \mathrm{~min}$ and then dehydrated in acetone at a series of concentrations. The sample was then embedded in embedding resin, followed by cutting into ultrathin sections with a microtome and leaduranium double staining. The prepared sections were observed and photographed under a transmission electron microscope (TEM) (JEOL, Tokyo, Japan).

Western blot analysis of protein expression. Cells were treated and collected according to the method explained above. Collected cells were lysed using cell lysis buffer and centrifuged at $10,500 \mathrm{x}$ g for $15 \mathrm{~min}$ at $4^{\circ} \mathrm{C}$ to collect the supernatant. The concentrations of extracted proteins were determined using BCA kit. A sample containing $40 \mu \mathrm{g}$ of proteins from each group was applied to SDS-PAGE electrophoresis and transferred to the membrane using a wet system. After the membrane was blocked with $10 \%$ skimmed milk powder, the TOPO I, Bax, Caspase-3 and GAPDH (dilution, 1:1,000) primary antibodies were added respectively, followed by overnight incubation at $4^{\circ} \mathrm{C}$. Then HRP-labeled secondary antibody (dilution, 1:2,000) was added, followed by incubation at room temperature for $2 \mathrm{~h}$, ECL darkroom development, and scanning.

Statistical analysis. The experimental data were expressed as mean \pm standard deviation, and were processed using SPSS 13.0 software (IBM Corp., Armonk, NY, USA). Differences between groups were analyzed using ANOVA single factor analysis of variance, and the difference was considered statistically significant at $\mathrm{P}<0.05$. The drug-drug interaction in the combination treatment was tested using the Jin (Zhengjun) formula: $\mathrm{q}=\mathrm{E}_{\mathrm{a}}+{ }_{\mathrm{b}} /\left(\mathrm{E}_{\mathrm{a}}+\mathrm{E}_{\mathrm{b}}-\mathrm{E}_{\mathrm{a}} \times \mathrm{E}_{\mathrm{b}}\right)$, where $\mathrm{E}_{\mathrm{a}}+{ }_{\mathrm{b}}$ represents the inhibition rate of the combination treatment, and $\mathrm{E}_{\mathrm{a}}$ and $\mathrm{E}_{\mathrm{b}}$ represent the inhibition rates of MA and CPT-11 treatments alone, respectively. If $0.85<\mathrm{q}<1.15$, it indicates the total effect was the sum of their individual effects. If $q>1.15$, it indicated a synergistic effect between the two drugs. If $\mathrm{q}<0.85$, it indicated that the two drugs had an antagonistic effect.

\section{Results}

Effect of MA in combination with CPT-11 on the proliferation of HT29 cells. The effects of MA and CPT-11 treatment alone and in combination on the proliferation of HT29 cells were examined using MTT assay. The results indicated that proliferation of HT29 cells was inhibited by MA and CPT-11 treatment alone and in combination (Table I). Additionally, the inhibition rate of the combination treatment was significantly higher than those of MA and CPT-11 treatment alone $(\mathrm{P}<0.01)$ at the same concentrations. Combination treatments of MA $(1 \mathrm{mg} / \mathrm{ml})$ with CPT-11 $(5 \mu \mathrm{g} / \mathrm{ml})$ and MA $(2 \mathrm{mg} / \mathrm{ml})$ with CPT-11 $(10 \mu \mathrm{g} / \mathrm{ml})$ had synergistic effects (q $>1.15)$.

Effect of MA in combination with CPT-11 on apoptosis of HT29 cells. In order to study the pro-apoptotic effect of drugs on HT29 cells and determining the underlying mechanism, a drug concentration at which cell proliferation is partially 
Table I. Effects of MA and CPT-11 treatment alone and in combination on proliferation of HT29 cells $(\mathrm{n}=5)$.

Drug concentration

\begin{tabular}{|c|c|c|c|c|c|}
\hline $\mathrm{MA}(\mathrm{mg} / \mathrm{ml})$ & CPT-11 $(\mu \mathrm{g} / \mathrm{ml})$ & OD value & Inhibition rate $(\%)$ & q-value & Drug-drug interaction \\
\hline 0 & 0 & $1.221 \pm 0.053$ & 0 & & \\
\hline 0.25 & 0 & $1.072 \pm 0.086$ & $12.20^{\mathrm{a}}$ & & \\
\hline 0.5 & 0 & $0.892 \pm 0.078$ & $26.95^{\mathrm{a}}$ & & \\
\hline 1 & 0 & $0.783 \pm 0.025$ & $35.87^{\mathrm{a}}$ & & \\
\hline 2 & 0 & $0.575 \pm 0.034$ & $52.91^{\mathrm{a}}$ & & \\
\hline 0 & 1.25 & $0.942 \pm 0.063$ & $22.85^{\mathrm{a}}$ & & \\
\hline 0 & 2.5 & $0.765 \pm 0.051$ & $37.35^{\mathrm{a}}$ & & \\
\hline 0 & 5 & $0.553 \pm 0.027$ & $54.71^{\mathrm{a}}$ & & \\
\hline 0 & 10 & $0.497 \pm 0.016$ & $59.29^{\mathrm{a}}$ & & \\
\hline 0.25 & 1.25 & $0.841 \pm 0.025$ & $31.08^{\mathrm{a}, \mathrm{b}}$ & 0.96 & Sum \\
\hline 0.5 & 2.5 & $0.522 \pm 0.042$ & $57.25^{\mathrm{a}, \mathrm{b}}$ & 1.06 & Sum \\
\hline 1 & 5 & $0.151 \pm 0.012$ & $87.61^{\mathrm{a}, \mathrm{b}}$ & 1.23 & Synergistic \\
\hline 2 & 10 & $0.057 \pm 0.007$ & $95.29^{\mathrm{a}, \mathrm{b}}$ & 1.19 & Synergistic \\
\hline
\end{tabular}

${ }^{a} \mathrm{P}<0.01$, compared with normal control; ${ }^{\mathrm{b}} \mathrm{P}<0.01$, compared with individual drug treatment alone at the same dose. MA, matrine; CPT-11, irinotecan.

inhibited was chosen. Thus, drug concentrations providing a $20-30 \%$ inhibition rate $\left(\mathrm{IC}_{20}-\mathrm{IC}_{30}\right)$ were considered appropriate for this experiment. Based on MTT results, the concentrations of $0.5 \mathrm{mg} / \mathrm{ml}$ for MA and $1.25 \mu \mathrm{g} / \mathrm{ml}$ for CPT-11 were chosen to evaluate the effects of the combination treatment on apoptosis of HT29 cells. Fig. 1 shows that the apoptosis rates in the normal control group, the MA group, the CPT-11 group and the combination treatment group were 2.82, 25.24, 22.93 and $45.03 \%$, respectively. Apoptosis rate in the combination treatment group was significantly higher than those registered in individual drug alone groups $(\mathrm{P}<0.01)$.

Effect of MA in combination with CPT-11 on the ultrastructure of HT29 cells. TEM results are shown in Fig. 2. Cells in the normal control group maintained cell membrane integrity. Microvilli were present on the membrane surface, while chromatin was distributed uniformly. Cells in the MA and the CPT-11 treatment alone groups underwent cell membrane blebbing, cell shrinkage, and chromatin condensation, which are characteristics for cells in apoptosis state. Cells in the combination treatment group suffered further membrane damage, and experienced nuclear fragmentation and formation of apoptotic bodies in the cells, showing a more severe apoptotic state.

Effect of MA in combination with CPT-11 on protein expression in HT29 cells. Western blot analysis results are presented in Fig. 3. MA treatment alone at $0.5 \mathrm{mg} / \mathrm{ml}$ was able to upregulate the expression of TOPO I significantly in HT29 cells. When MA was used in combination with CPT-11, the upregulation of TOPO I expression was even higher $(\mathrm{P}<0.01)$. Compared with the normal control group, groups of MA treatment alone, CPT-11 treatment alone and combination treatment all had significantly higher levels of Bax and Caspase-3 expression $(\mathrm{P}<0.01)$. Bax and Caspase-3 expression levels in the

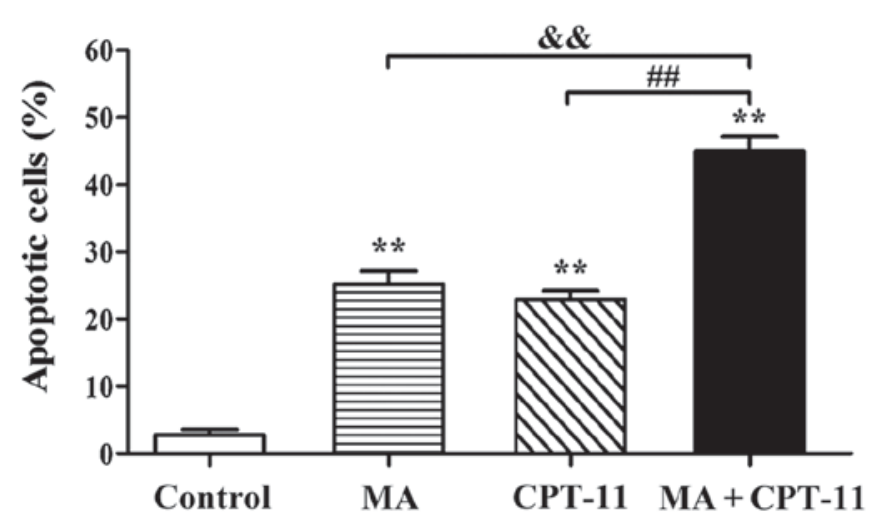

Figure 1. Flow cytometry measurement of apoptosis rates of different treatment groups. ${ }^{* *} \mathrm{P}<0.01$, compared with normal control group; ${ }^{\&} \mathrm{P}<0.01$, combination treatment group compared with MA treatment alone group; ${ }^{\# \#} \mathrm{P}<0.01$, combination treatment group compared with CPT-11 treatment alone group. MA, matrine; CPT-11, irinotecan.

combination treatment group were higher than the individual drug treatment alone groups $(\mathrm{P}<0.01)$.

\section{Discussion}

Colon cancer is a malignant tumor with relatively higher incidence, and the incidence is on the increase annually in China due to the change in eating habits (11). Due to the absence of any obvious early clinical symptoms, many patients with colon cancer are usually diagnosed when the disease is already in late-stage and is already too late for surgical intervention (12). Chemotherapy is the main treatment method for late-stage colon cancer. Currently 5-FU in combination with oxaliplatin or CPT-11 is the most common chemotherapy regimen used in clinic. However, many adverse effects of 

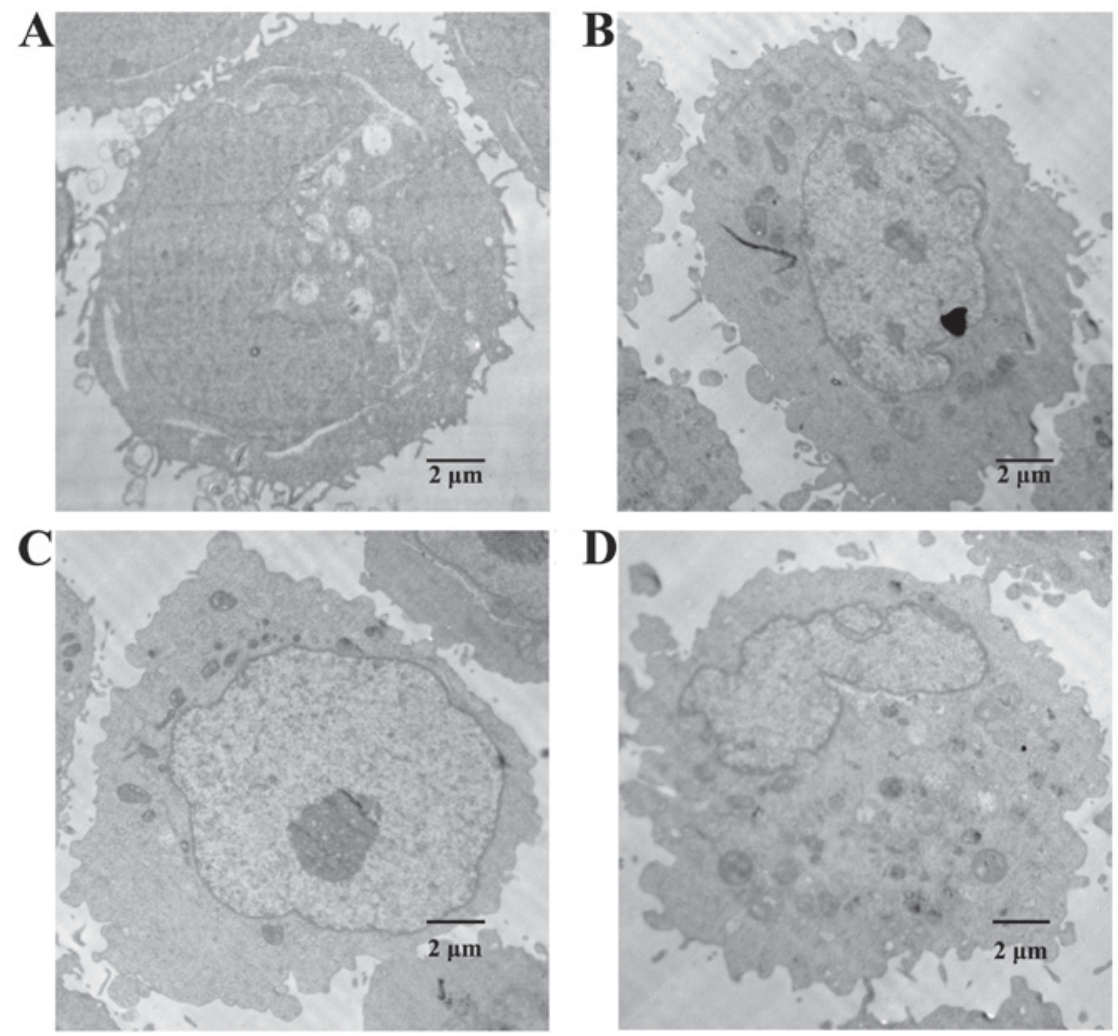

Figure 2. Ultrastructures of HT29 cells in different treatment groups by TEM. (A) The normal control group, (B) the MA treatment alone group, (C) the CPT-11 treatment alone group, and (D) the combination treatment group. TEM, transmission electron microscopy; MA, matrine; CPT-11, irinotecan.

A

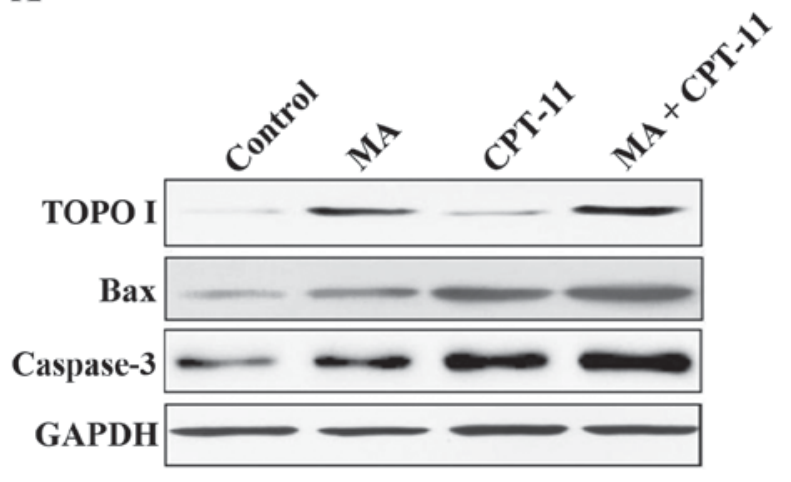

B

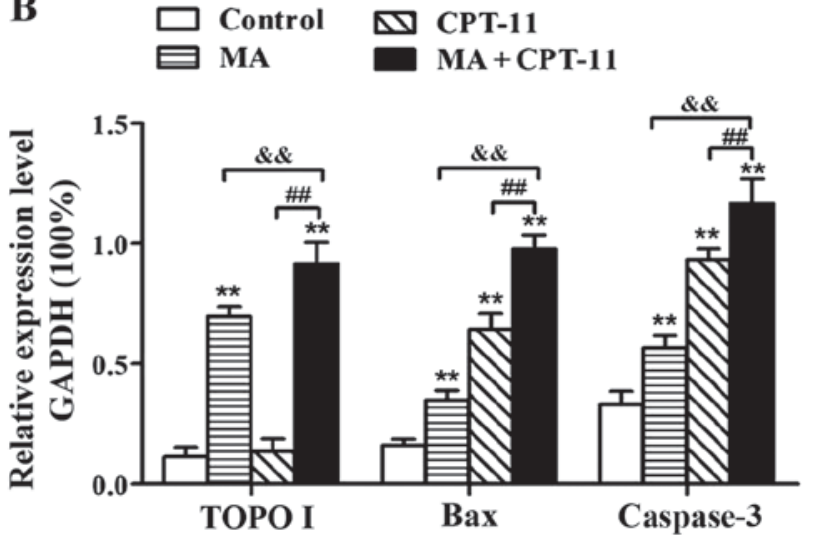

Figure 3. Western blot analysis of protein expression in HT29 cells. (A) Western blot analysis bands of TOPO I, Bax and Caspase-3, and (B) gray-scale quantification of TOPO I, Bax and Caspase-3. ${ }^{* *} \mathrm{P}<0.01$, compared with the normal control group; ${ }^{\& \&} \mathrm{P}<0.01$, the combination treatment group compared with the MA treatment alone group; ${ }^{\#} \mathrm{P}<0.01$, the combination treatment group compared with the CPT-11 treatment alone group. TOPO, topoisomerase; MA, matrine; CPT-11, irinotecan.

chemotherapeutic drugs may seriously affect patients' quality of life (13).

Large-scale clinical trials indicated that CPT-11 treatment of advanced colorectal cancer can achieve an efficiency of approximately $49 \%$, mainly due to primary or secondary drug resistance to CPT-11 (14). It was found that CPT-11 can be metabolized into an active metabolite known as SN-38 in human body, which can specifically bind to TOPO in tumor cells, inhibit its activity, and eventually induce apoptosis (4). DNA TOPOs are ubiquitous enzymes in the cell nucleus that can catalyze the cleavage and ligation of DNA strands, thereby regulating the topological state of DNA (15). Recent studies revealed that the downregulation of TOPO expression in tumor cells could be the main reason for resistance to CPT-11. This may reduce the drug target sites and ultimately results in a reduction in CPT-11 efficiency (3).

It was reported that MA can inhibit tumor cell proliferation through various mechanisms, such as inducing cancer cell differentiation and apoptosis, altering tumor cell cycle, and inhibiting telomerase activity (16). Unlike most chemotherapy 
drugs, MA does not harm normal cell growth and division. Moreover, it can improve the number of white blood cells in patients and enhance the patient's immune system (17).

Most chemotherapy drugs can induce apoptosis in tumor cells. Apoptosis is a process of programmed cell death that is regulated by multiple intercellular and intracellular signals $(18,19)$. Apoptosis is characterized by cell shrinkage, membrane blebbing, intracellular endonuclease activation, chromosomal DNA degradation, DNA fragmentation, nuclear/chromatin condensation, and formation of apoptotic bodies in cells $(20,21)$. BAX is a pro-apoptotic protein on the outer mitochondrial membrane. It can form homo- or heterodimers with other pro-apoptotic members BAK or tBid to disrupt the mitochondrial membrane, leading to the release of cytochrome $\mathrm{c}$ into the cytoplasm and then a series of intracellular apoptotic responses (22). Apoptosis is a complex physiological process involving multiple genes. Caspase-3 plays an important role in the process of apoptosis. When intracellular Caspase- 3 is activated, the cell enters into the process of irreversible apoptosis (23).

In the present study, MA and CPT-11 treatments alone were found to inhibit cell proliferation and induce apoptosis in HT29 cells. The combination treatment exhibited a higher inhibition rate compared with individual drug treatment alone at corresponding concentrations. Moreover, the combination treatments of MA at $1 \mathrm{mg} / \mathrm{ml}$ with CPT- 11 at $5 \mu \mathrm{g} / \mathrm{ml}$ and MA at $2 \mathrm{mg} / \mathrm{ml}$ with CPT-11 at $10 \mu \mathrm{g} / \mathrm{ml}$ had synergistic effects. AV-PI double staining flow cytometry and TEM results showed that the combination treatment also synergistically induced apoptosis. Western blot analysis results suggested that CPT-11 treatment alone did not induce TOPO I expression, while MA treatment alone was able to induce TOPO I expression. When MA was administered in combination with CPT-11, TOPO I expression in HT29 cells was substantially upregulated. Additionally, Bax and Caspase-3 expression levels in combination treatment was significantly higher than those in MA and CPT-11 treatments alone. Results obtained in this study were comparable to those reported in another clinical study (10), and proved at the molecular level that MA can enhance the inhibition of colorectal cancer in combination with CPT-11.

In conclusion, a possible mechanism of synergistic effect of MA in combination with CPT-11 is proposed. Firstly, MA upregulated the expression of TOPO I, which increased the number of target sites for CPT-11, thus enhanced the inhibitory effect of CPT-11 on HT29 cells. In addition, the combination treatment upregulated the expression of Bax and Caspase-3, activating the apoptosis signal pathways in HT29 cells. The present study provided the experimental basis for clinical application of MA in combination with CPT-11 in the treatment of colon cancer.

\section{References}

1. Fang XL: Study the curative effect of advanced stage colon carcinoma treated by L-OHP combined with $5-\mathrm{FU} / \mathrm{CF}$. Chin J Clin Ration Drug Use 2: 8-9, 2009 (In Chinese).

2. Sileri P, D'Ugo S, Benavoli D, Stolfi VM, Palmieri G, Mele A and Gaspari AL: Metachronous splenic metastasis from colonic carcinoma five years after surgery: a case report and literature review. South Med J 102: 733-735, 2009.
3. Zhang MQ, Lin X, Li Y and Lu S: Irinotecan as a second-line chemotherapy for small cell lung cancer: a systemic analysis. Asian Pac J Cancer Prev 16: 1993-1995, 2015.

4. Phelps MA and Sparreboom A: Irinotecan pharmacogenetics: a finished puzzle? J Clin Oncol 32: 2287-2289, 2014.

5. Chen MC, Lee NH, Hsu HH, Ho TJ, Tu CC, Chen RJ, Lin YM, Viswanadha VP, Kuo WW and Huang CY: Inhibition of $\mathrm{NF}-\kappa \mathrm{B}$ and metastasis in irinotecan (CPT-11)-resistant LoVo colon cancer cells by thymoquinone via JNK and p38. Environ Toxicol 32: 669-678, 2017.

6. Chui CH, Lau FY, Tang JC, Kan KL, Cheng GY, Wong RS, Kok SH, Lai PB, Ho R, Gambari R and Chan AS: Effects of matrine and oxymatrine on the proliferation and the apoptosis of A549 cells. Acad Thi Med Univ 26: 778-780, 2004.

7. Zhang J, Li Y, Chen X, Liu T, Chen Y, He W, Zhang Q and Liu S: Autophagy is involved in anticancer effects of matrine on SGC-7901 human gastric cancer cells. Oncol Rep 26: 115-124, 2011.

8. Li H, Tan G, Jiang X, Qiao H, Pan S, Jiang H, Kanwar JR and Sun X: Therapeutic effects of matrine on primary and metastatic breast cancer. Am J Chin Med 38: 1115-1130, 2010.

9. Huang J, Chen KJ and Zhang W: Effect of matrine on inhibiting proliferation and inducing apoptosis of human intestinum crassum carcinoma HT29 cells. Chin Tradit Herbal Drugs 38: 1210-1214, 2007.

10. Ren H, Zhang S, Ma H, Wang Y, Liu D, Wang X and Wang Z: Matrine reduces the proliferation and invasion of colorectal cancer cells via reducing the activity of p38 signaling pathway. Acta Biochim Biophys Sin (Shanghai) 46: 1049-1055, 2014.

11. Gordon MB, Nakhle S and Ludlam WH: Patients with acromegaly presenting with colon cancer: a case series. Case Rep Endocrinol 2016: 5156295, 2016.

12. Lujan HJ, Plasencia G, Jacobs M, Viamonte M III and Hartmann RF: Long-term survival after laparoscopic colon resection for cancer: complete five-year follow-up. Dis Colon Rectum 45: 491-501, 2002.

13. Zhang Y, Zhang H, Yu P, Liu Q, Liu K, Duan H, Luan G, Yagasaki $\mathrm{K}$ and Zhang G: Effects of matrine against the growth of human lung cancer and hepatoma cells as well as lung cancer cell migration. Cytotechnology 59: 191-200, 2009.

14. Ismaili N: Treatment of colorectal liver metastases. World J Surg Oncol 9: 154, 2011.

15. Pommier Y: Topoisomerase I inhibitors: camptothecins and beyond. Nat Rev Cancer 6: 789-802, 2006.

16. Zhang LP, Jiang JK, Tam JWO, Zhang Y, Liu XS, Xu XR, Liu BZ and He YJ: Effects of matrine on proliferation and differentiation in K-562 cells. Leuk Res 25: 793-800, 2001.

17. Zhang JQ, Li YM, Liu T, He WT, Chen YT, Chen XH, Li X, Zhou WC, Yi JF and Ren ZJ: Antitumor effect of matrine in human hepatoma $\mathrm{G} 2$ cells by inducing apoptosis and autophagy. World J Gastroenterol 16: 4281-4290, 2010.

18. Indran IR, Tufo G, Pervaiz S and Brenner C: Recent advances in apoptosis, mitochondria and drug resistance in cancer cells. Biochim Biophys Acta 1807: 735-745, 2011.

19. Heit B, Yeung T and Grinstein S: Changes in mitochondrial surface charge mediate recruitment of signaling molecules during apoptosis. Am J Physiol Cell Physiol 300: C33-C41, 2011.

20. Lee YS, Jin DQ, Kwon EJ, Park SH, Lee ES, Jeong TC, Nam DH, Huh K and Kim JA: Asiatic acid, a triterpene, induces apoptosis through intracellular $\mathrm{Ca}^{2+}$ release and enhanced expression of p53 in HepG2 human hepatoma cells. Cancer Lett 186: 83-91, 2002.

21. Venkatesan P, Bhutia SK, Singh AK, Das SK, Dash R, Chaudhury K, Sarkar D, Fisher PB and Mandal M: AEE788 potentiates celecoxib-induced growth inhibition and apoptosis in human colon cancer cells. Life Sci 91: 789-799, 2012.

22. Jeong JC, Kim MS, Kim TH and Kim YK: Kaempferol induces cell death through ERK and Akt-dependent down-regulation of XIAP and survivin in human glioma cells. Neurochem Res 34: 991-1001, 2009.

23. Li Z, Jo J, Jia JM, Lo SC, Whitcomb DJ, Jiao S, Cho K and Sheng M: Caspase-3 activation via mitochondria is required for long-term depression and AMPA receptor internalization. Cell 141: 859-871, 2010. 